\title{
Spatial Variation in Physicochemical Surface Water Quality in River Rwizi, Western Uganda
}

\author{
Ojok Walter ${ }^{1,2}$, John Wasswa3 ${ }^{3}$, Caroline K. Nakiguli1 ${ }^{1}$ Emmanuel Ntambi ${ }^{*}$ \\ ${ }^{1}$ Department of Chemistry, Faculty of Science, Mbarara University of Science and Technology, Mbarara, Uganda \\ ${ }^{2}$ Department of Chemistry, Faculty of Science, Muni University, Arua, Uganda \\ ${ }^{3}$ Department of Chemistry, College of Natural Sciences, Makerere University, Kampala, Uganda \\ Email: *emmantambi@must.ac.ug
}

How to cite this paper: Walter, O., Wasswa, J., Nakiguli, C.K. and Ntambi, E. (2019) Spatial Variation in Physicochemical Surface Water Quality in River Rwizi, Western Uganda. Journal of Water Resource and Protection, 11, 1427-1440.

https://doi.org/10.4236/jwarp.2019.1112083

Received: October 1, 2019

Accepted: December 1, 2019

Published: December 4, 2019

Copyright (c) 2019 by author(s) and Scientific Research Publishing Inc. This work is licensed under the Creative Commons Attribution International License (CC BY 4.0).

http://creativecommons.org/licenses/by/4.0/

\begin{abstract}
River Rwizi originates from the Buhweju hills. It is a major source of water for the inhabitants of Mbarara Municipality and surrounding environment. In this study, spatial variation of water quality in River Rwizi section within Mbarara Municipality was determined using cluster analysis. Laboratory analysis was conducted on water samples from five sites along the river section using standard methods for: $\mathrm{pH}, \mathrm{EC}$, TSS, TDS, turbidity, temperature, total hardness, alkalinity, salinity, colour, $\mathrm{NH}_{3}-\mathrm{N}, \mathrm{SO}_{4}^{2-}$, $\mathrm{BOD}, \mathrm{COD}, \mathrm{DO}, \mathrm{Ca}$, $\mathrm{Mg}, \mathrm{Fe}$, and $\mathrm{Mn}$. Cluster analysis grouped the study sites into slight pollution (Spencon, GBK), moderate pollution (Katete) and high pollution (BSU, Kakoba) for dry season. For rain season, order was: slight pollution (BSU, Spencon), moderate pollution (GBK) and high pollution (Kakoba, Katete), basing on similarity of water quality variables. These results show that water pollution resulted primarily from domestic waste water, agricultural runoff and industrial effluents. Thus, water from River Rwizi is not suitable for drinking in both dry and wet seasons.
\end{abstract}

\section{Keywords}

River Rwizi, Cluster Analysis, Spatial Variation, Pollution

\section{Introduction}

Water is one of the most important requirements for the sustenance and continuation of life. It is therefore important that good quality water should be available for domestic, agricultural and industrial activities. However, this is increasingly becoming difficult mainly due to large scale pollution caused by agricultural, industrial and domestic activities which generate and dispose a range of 
inorganic and organic pollutants into the water pathways.

Recently, deterioration of surface water quality has attracted a lot of research due to health hazards accruing from contaminated water. This deterioration has been attributed to both natural processes such as weathering of underlying crustal materials, erosion, precipitation and anthropogenic activities which are triggered by climate change, agricultural land use, industrial and sewage effluent discharge [1] [2]. Anthropogenic activities are major contributors of pollutants to surface water resources in developing countries such as Uganda, the most important being urban sewage, agriculture and industrial effluents which are well known for nutrient loading and heavy metal pollution of water bodies [3] [4] [5]. Moreover, river water resources are important in promoting human development as they serve as domestic water sources; provide water for agriculture, industries and transport. However, the rivers are turned into dumping ground for wastes, especially in African countries like Uganda. As a result, their water quality is affected significantly by solid and liquid wastes from industries, homesteads, sewage, erosion and waste from agricultural fields [3]. This makes rivers to become susceptible to pollution from urban, industrial and agricultural activities that occur in their water sheds. The situation is made worse by turning of wetlands (filtering system through the use of roots of papyrus reeds) into agricultural fields.

Thus, information on water quality and pollution sources in such water bodies is important for the implementation of sustainable water use management strategies. For effective maintenance of water quality through appropriate control measures, continuous monitoring of a large number of quality parameters is essential [6]. In addition, due to seasonality and regionality of river water, assessing spatial-temporal variations in water quality has become an important aspect of river water quality at a watershed level, a key aspect for the physico-chemical characterization of aquatic environments [1] [4]. The studies in Uganda have shown that most water resources are easily contaminated due to anthropogenic activities especially in urban areas. A case in point is the deterioration of water quality of River Rwizi that has been reported over the past several years by a number of researchers [5] [7] [8]. River Rwizi originates from the hills of Buhweju District and crosses through several other districts of south western Uganda including Mbarara, Bushenyi, Sheema, Ntungamo, Kibingo, and Kiruhura among others, with various tributaries originating from different parts of the region. As a result, the river is an important water resource in south western Uganda serving thousands of people as source of drinking water for humans and animals, source of materials for crafts making and home to numerous forms of life [7] [9]. It eventually pours its waters into Lake Victoria via the network of the Kooki lakes system such as Mburo, Kachera, Nakivale, and Kijanebarola, among others. Interestingly, most industries in south western Uganda have no proper treatment facilities and are situated in the proximity of River Rwizi and its tributaries. Domestic and institutional effluents are directed into the river and the untreated sewage which is pushed into the lagoons with no further manage- 
ment over pours whenever it rains. This makes the river to become susceptible to pollution. With the escalating poor industrial development in Uganda, this problem is bound to even become more severe in the near future. In addition, the river is under enormous threat and is gradually dying due to impact of anthropogenic activities [7]. The river section in Mbarara Municipality is selected for this study because it has the highest proliferation of industrial establishments, and is likely to experience the serious consequences of pollution. Many studies have been conducted on the River Rwizi water with results indicating deterioration in its quality mainly attributable to anthropogenic activities in its water shed [5] [7].

Previously there has not been any report on assessment of spatial variations in physico-chemical parameters of water in River Rwizi, yet any significant variations in physico-chemical parameters affect the quality of a water resource at a given point. Hence, it was necessary to obtain information on the spatial variation of physico-chemical characteristics of water in River Rwizi in order to provide baseline information for a monitoring program for water resources in Uganda and design of proper treatment strategy for drinking water. Therefore, this current study evaluated the spatial variation of water quality in the dry and wet seasons, of River Rwizi section in Mbarara Municipality.

\section{Materials and Methods}

\subsection{Location of Study Area}

The study area (Figure 1) is located in Mbarara Municipality found in Mbarara district, south western Uganda, at an altitude varying from $1261 \mathrm{~m}$ above sea level

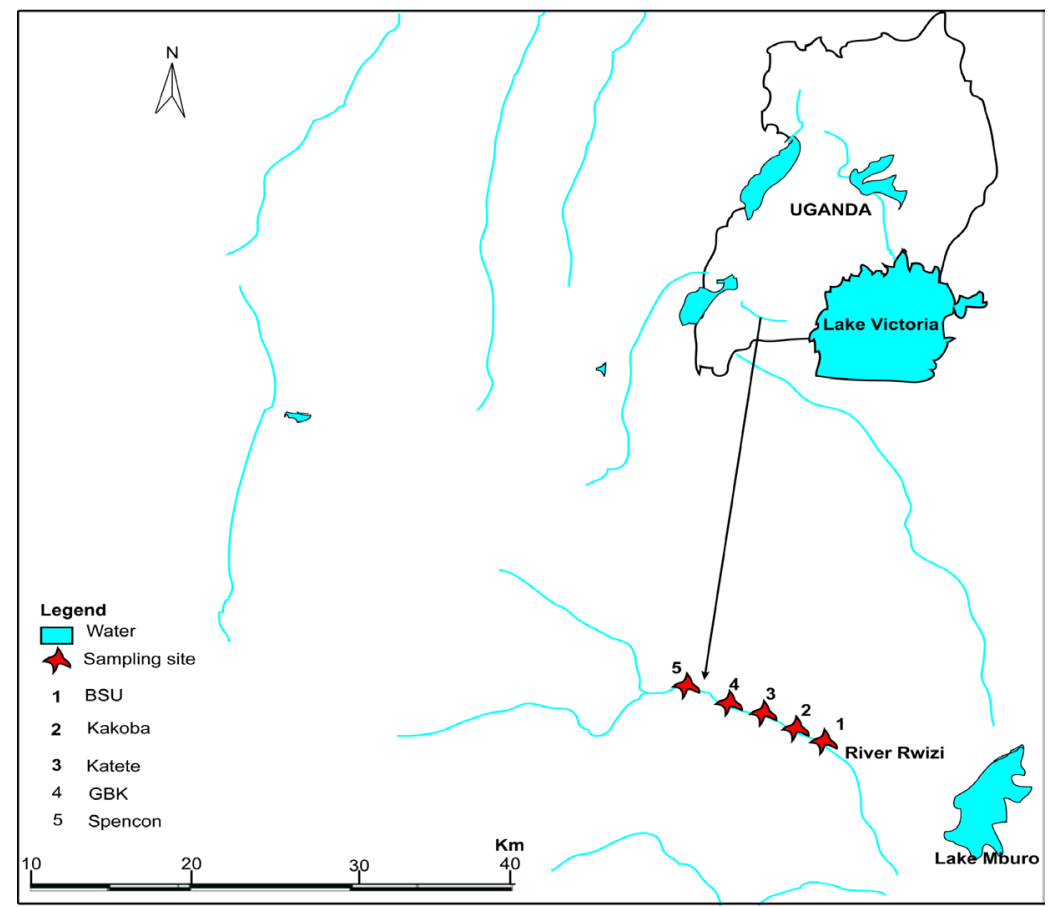

Figure 1. The study section of River Rwizi in Mbarara Municipality. 
at the outlet to $2168 \mathrm{~m}$ above sea level at the very northern part of the catchment with average elevation of $1517 \mathrm{~m}$ above sea level. The study stretched from Spencon Water Treatment Works (site 5) at coordinate $0^{\circ} 374.69^{\circ} \mathrm{S}, 030^{\circ} 372.76^{\circ} \mathrm{E}$, where the river enters the Municipality to the out flow point just below Bishop Stuart University-BSU (site 1 ) at coordinates $0^{\circ} 36^{\prime} 30.32^{\circ} \mathrm{S}, 030^{\circ} 41^{\prime} 51.13^{\circ} \mathrm{E}$. The Rwizi catchment covers an approximate area of $2521 \mathrm{~km}^{2}$. Sampling site selection criteria included natural conditions as well as points with human activities. BSU (Site 1) is where water leaves the study section of the River. Kakoba (site 2), Katete (site 3), and GBK (site 4) are affected by almost all types of wastes from residential, institutional, agricultural, and industrial activities. Kakoba site has steel rolling mill, dairy processing plant, sewage lagoons and a market near it while there are sewage lagoons near Katete site which collect sewage and waste water from Mbarara Regional Referal Hospital (MRRH), and its surroundings. GBK site has dairy processing plants, abattoir and market area. Spencon site (5) represents the water entering into the study area where there is less anthropogenic influence.

\subsection{Water Sampling}

Water samples were taken from five sites that are well distributed with separation of approximately $4 \mathrm{~km}$ apart. The sampling sites were chosen purposively basing on the intensity of anthropogenic activities in the study area, in two seasons (March-May) for dry season and (July-October) 2012 for wet season. Sampling, preservation and transport were carried out following standard protocols [10]. The collected water samples were kept in cleaned 1.5-litre polythene plastic bottles. Each site was sampled in triplicate and mixed to obtain a homogeneous sample, once a month for six months. Before sampling, the bottles and caps were cleaned with spectroscopic nitric acid and then rinsed three times with water at the sampling sites. The samples were subsequently stored in 1.5-litre plastic bottles in ice boxes at $4^{\circ} \mathrm{C}$ for approximately 3 hours before analysis to minimize physico-chemical changes.

\subsection{Physico-Chemical Parameter Measurements}

Laboratory analyses of nineteen physico-chemical parameters were generally performed following standard protocols [10] [11]. Colour was measured using the platinum-cobalt standard method using $\mathrm{HACH} \mathrm{DR} / 2010$ spectrometer [3]. Hardness, alkalinity and sulphate were determined by titration using ethylene diamine tetra acetic acid (EDTA), sulphuric acid and barium chloride solution respectively [10]. Temperature, electrical conductivity, $\mathrm{pH}$, salinity of the water samples were measured at the sampling sites by using multi-parameter HANNA instrument (Model HI9811-5) [3]. Titration with EDTA was also used to determine the concentration of calcium and magnesium in the water samples [10]. Ammonia-nitrogen was determined following the Nessler method using DR/2010 spectrophotometer [10]. Dissolved oxygen was measured using the DO bottle 
method [11].

Biological oxygen demand $\left(\mathrm{BOD}_{5}\right)$ was determined using the dilution method [10] and chemical oxygen demand (COD) was determined using the $\mathrm{HACH}$ $\mathrm{DR} / 2010$ spectrophotometer after digesting the water with potassium dichromate [10]. Turbidity was measured using the $\mathrm{HACH}$ 2100AN turbidimeter; while iron and manganese were determined using graphite flame atomic absorption spectrophotometer at wavelength $248.3 \mathrm{~nm}$ and $279.5 \mathrm{~nm}$ respectively [11]. All the determinations were done in triplicates.

\subsection{Statistical and Cluster Analysis}

Statistical analysis was done by SPSS package 16.0 to compute the average concentrations of the determined physico-chemical parameters and standard deviation; while cluster analysis was performed using Past software. Cluster analysis (CA) is an assortment of techniques designed to perform classification by assigning observation to groups so that each is more or less homogenous and distinct from other groups. It is a group of multivariate statistical techniques whose primary purpose is to assemble objects based on the characteristics they possess [12] [13]. Its primary purpose is to classify the objects of a system into categories or clusters based on their similarities. The aim is to find an optimal grouping for which the observations or objects within each cluster are similar, but the clusters are dissimilar to each other. Hierarchical clustering is the most common approach in which clusters are formed sequentially. The most similar objects are first grouped, and these initial groups are merged according to their similarities. Eventually as the similarity decreases all subgroups are merged into a single cluster [4] [13]. Cluster analysis is applied in this study to the water quality data obtained in the two seasons, using a single linkage distance method.

In the single linkage distance method, the distance or similarities between two clusters $\mathrm{A}$ and $\mathrm{B}$ are defined as the minimum distance between a point in $\mathrm{A}$ and a point in $\mathrm{B}$ :

$$
D(A, B)=\min \left\{d\left(x_{i}+x_{j}\right) \text {, for } x_{i} \text { in } \mathrm{A} x_{j} \text { in } B\right\}
$$

where: $d\left(x_{i}+x_{j}\right)$ is the Euclidean distance

At each step, the distance is found for every pair of clusters and the two clusters with the smallest distance (large similarity) are merged. After two clusters are merged the procedure is repeated for the next step: the distances between all pairs of clusters are calculated again; and the pair with minimum distance is merged into a single cluster. The result of a hierarchical clustering procedure can be displayed using a tree diagram, also known as a dendogram. Generally, prior to cluster analysis data is normalized and the weight per group method is applied in Euclidean distance calculation. The Euclidean distance gives the similarity between two samples and a distance can be represented by the difference between analytical values from the samples [4]. Hence, CA is generally a generic name for a group of techniques that place objects or units in groups or clusters in an objective manner based only on similarities in the data rather than any a 
priori groupings. The aim is to find groupings of units such that all units in a group are relatively similar to one another; based on similarities or dissimilarity measures calculated from the data [4] [13] [14]. The first task in any cluster analysis is to decide how to measure similarity or closeness between the units for which groupings are required. For the $i^{\text {th }}$ and $s^{\text {th }}$ object measured on variables $x_{1}, \cdots, x_{p}$, it is defined as

$$
D_{r s}=\sqrt{\sum_{j}\left(X_{r j}-X_{s j}\right)^{2}}
$$

The next stage in the analysis is to adopt a mathematical criterion-the clustering algorithm to convert the dissimilarity matrix to a clustering of the objects. Hierarchical clustering methods are agglomerative. The objects all start in different clusters and then the two closest objects are merged in a single cluster. Single linkage (or the nearest neighbour) measures the distance between closest members in different clusters. In scientific studies where the objects or units are described by a multivariate set of measured variables, the measure of similarity or dissimilarity can be derived from the data easily by calculating the Euclidean distance between pairs of objects. The Euclidean distance is a multivariate generalization of the Pythagorean Theorem.

The spatial variability of physico-chemical water quality in the whole section of River Rwizi in Mbarara Municipality is determined from Cluster Analysis using the linkage distance, reported as Dlink/Dmax which represents the quotient between the linkage distances for a particular case divided by the maximal linkage distance [4] [13] [14].

\section{Results and Discussion}

For the dry season, colour, turbidity, TSS, TDS of the River Rwizi water are in the range 670 - $905 \mathrm{PtCo}, 96$ - 365.3 NTU, and 41.3 - $209.3 \mathrm{mg} / \mathrm{L} 51.4-67.2 \mathrm{mg} / \mathrm{L}$ respectively, with all sites recording turbidity above WHO regulatory limit (Table 1a) [15]. This can be attributed to river sand mining, geogenic release of oxides of iron and manganese and washing bays. In addition, erosion had some contribution to deterioration in water clarity of the river in the wet season. The decrease in TSS from $46 \mathrm{mg} / \mathrm{L}$ at Spencon site to $43 \mathrm{mg} / \mathrm{L}$ at BSU site and colour from 887 PtCo to 830 PtCo at these sites respectively, during the dry season, shows water clarity as a result of River Rwizi water being amended in the river course downstream. $\mathrm{pH}$ ranged from $5.9-6.9$, with all study sites recording values below the WHO allowable limit of $(6.5-8.5)$ in drinking water [15] [16]. This could be a result of hydrolysis reactions of highly charged cations such as $\mathrm{Fe}^{3+}$, acidic gases and decomposition of organic matter. Generally, water quality parameters are higher for most study sites for the wet season than in the dry season due to erosion (Table 1b). The turbidity, iron, EC, salinity of the river water increased suddenly from $92.7 \mathrm{NTU}, 0.511,0.053 \mathrm{mg} / \mathrm{L}$ at Spencon site to $365.3 \mathrm{NTU}, 0.737$, $0.097 \mathrm{mg} / \mathrm{L}$ at GBK site in the wet season respectively, indicative of the pollution effect of the dairy factories located near the GBK site, which release raw industrial 
Table 1. Physico-chemical surface water quality parameters of River Rwizi. (a) Dry season; (b) wet season.

(a)

\begin{tabular}{cccccccc}
\hline Parameter & BSU & Kakoba & Katete & GBK & Spencon & Mean & SD \\
\hline Colour (PtCo) & 830 & 757 & 670 & 890 & 887 & 806.8 & 93.7 \\
Turbidity (NTU) & 105 & 101.3 & 100 & 96 & 98.3 & 100.12 & 3.4 \\
TSS (mg/L) & 43 & 42 & 44.3 & 41.3 & 46 & 43.3 & 1.9 \\
Hardness (mg/L) & 56.7 & 56 & 57.3 & 49.7 & 53 & 54.5 & 3.2 \\
Alkalinity (mg/L) & 29.3 & 33 & 56.3 & 22 & 25.3 & 33.2 & 13.6 \\
pH & 6.74 & 6.73 & 6.92 & 6.51 & 6.63 & 6.71 & 0.2 \\
TDS (mg/L) & 52.53 & 53.27 & 51.4 & 54.6 & 58.37 & 54.03 & 2.7 \\
EC $(\mu \mathrm{s} / \mathrm{cm})$ & 101.13 & 107.07 & 104.73 & 108.07 & 102.33 & 104.67 & 3.0 \\
Salinity (mg/L) & 0.053 & 0.053 & 0.053 & 0.06 & 0.053 & 0.05 & 0.0 \\
Temperature ( $\left.{ }^{\circ} \mathrm{C}\right)$ & 22.73 & 22.57 & 22.5 & 22.63 & 22.63 & 22.61 & 0.1 \\
Sulphate (mg/L) & 14.67 & 12.33 & 12 & 10.67 & 10.33 & 12.00 & 1.7 \\
COD (mg/L) & 115 & 138.7 & 186.3 & 60.7 & 143.3 & 128.8 & 45.9 \\
BOD (mg/L) & 43 & 53 & 84 & 45.3 & 37.7 & 52.60 & 18.4 \\
DO (mg/L) & 9.55 & 10.44 & 12.67 & 6.73 & 6.48 & 9.17 & 2.6 \\
NH ${ }_{3}-\mathrm{N}(\mathrm{mg} / \mathrm{L})$ & 10.81 & 10.51 & 9.49 & 6.01 & 5.66 & 8.50 & 2.5 \\
$\mathrm{Mg}(\mathrm{mg} / \mathrm{L})$ & 7.33 & 10.33 & 9.67 & 8 & 8 & 8.67 & 1.27 \\
$\mathrm{Ca}(\mathrm{mg} / \mathrm{L})$ & 18 & 10.67 & 9.33 & 8.33 & 7 & 10.67 & 4.31 \\
$\mathrm{Fe}(\mathrm{mg} / \mathrm{L})$ & 0.517 & 0.514 & 0.541 & 0.502 & 0.573 & 0.529 & 0.028 \\
$\mathrm{Mn}(\mathrm{mg} / \mathrm{L})$ & 0.114 & 0.143 & 0.0473 & 0.123 & 0.049 & 0.095 & 0.044 \\
\hline
\end{tabular}

(b)

\begin{tabular}{cccccccc}
\hline Parameter & BSU & Kakoba & Katete & GBK & Spencon & Mean & SD \\
\hline Colour (PtCo) & 699 & 905 & 872 & 749 & 651 & 775.2 & 109.701 \\
Turbidity (NTU) & 98.7 & 176.3 & 124.7 & 365.3 & 92.7 & 171.54 & 113.227 \\
TSS (mg/L) & 44.7 & 123.3 & 71.7 & 209.3 & 97.8 & 109.36 & 63.078 \\
Hardness (mg/L) & 62 & 62.3 & 62 & 66 & 61.4 & 62.74 & 1.851 \\
Alkalinity (mg/L) & 28.7 & 39.3 & 86 & 40 & 45.5 & 47.9 & 22.149 \\
pH & 5.92 & 5.93 & 5.9 & 5.92 & 5.96 & 5.926 & 0.022 \\
TDS (mg/L) & 53.2 & 55.2 & 65.5 & 67.2 & 51.6 & 58.54 & 7.268 \\
EC ( $\mu$ s/cm) & 103.93 & 113.4 & 105.3 & 195.8 & 95.6 & 122.81 & 41.290 \\
Salinity (mg/L) & 0.053 & 0.067 & 0.057 & 0.097 & 0.053 & 0.065 & 0.019 \\
Temeperature ( $\left.{ }^{\circ} \mathrm{C}\right)$ & 23.07 & 23.13 & 22.83 & 23 & 22.73 & 22.952 & 0.167 \\
Sulphate (mg/L) & 9.48 & 9.07 & 10.67 & 8.41 & 9.33 & 9.392 & 0.824 \\
COD (mg/L) & 143.7 & 240 & 284.7 & 302 & 89.7 & 212.02 & 91.912 \\
BOD (mg/L) & 59 & 65.3 & 101.7 & 103.7 & 48 & 75.54 & 25.565 \\
DO (mg/L) & 17.41 & 21.55 & 25.35 & 23.1 & 15.11 & 20.50 & 4.183 \\
NH3-N (mg/L) & 15.73 & 16.65 & 20.3 & 11.3 & 10.53 & 14.90 & 4.030 \\
Mg (mg/L) & 6.73 & 7.55 & 7.16 & 5.83 & 5.51 & 6.556 & 0.867 \\
Ca (mg/L) & 10.15 & 8.92 & 8.28 & 7.34 & 7.22 & 8.38 & 1.211 \\
Fe (mg/L) & 0.663 & 0.407 & 0.554 & 0.737 & 0.511 & 0.574 & 0.129 \\
Mn (mg/L) & 0.145 & 0.181 & 0.077 & 0.079 & 0.103 & 0.117 & 0.045 \\
\hline & & & & & & & \\
\hline
\end{tabular}


waste water into the river. The DO varied from $6.48-25.35 \mathrm{mg} / \mathrm{L}$ which is above the regulatory standard proposed by USEPA [16] [17]. This may be attributed to the temperature, turbulence of water as it flows along the river course, salinity as well as altitude.

The sudden increase in $\mathrm{NH}_{3}-\mathrm{N}$ from $11.3 \mathrm{mg} / \mathrm{L}$ at $\mathrm{GBK}$ site to $20.3 \mathrm{mg} / \mathrm{L}$ at Katete site may be due to release of raw sewage into the river in the wet season. Even though there is sewerage system where urban sewage and run-off are collected in the sewers, excessive rainfall of the wet season leads to an overflow of Katete sewage lagoons.

According to WHO drinking water standards [15], BOD value should not exceed $6 \mathrm{mg} / \mathrm{L}$, and $3 \mathrm{mg} / \mathrm{L}$ for aquaculture. The $\mathrm{BOD}_{5}$ which is in the range 37.7 $103.7 \mathrm{mg} / \mathrm{L}$, indicated that all sites had high BOD values above WHO [15] regulatory limit of $6 \mathrm{mg} / \mathrm{L}$ for drinking water and fisheries. It is particularly higher at all sites as the water flows from Spencon site to BSU site. High BOD is undesirable in water because it will result in reduction in dissolved oxygen level. This may be due to the decomposition of organic matter by micro-organisms which consume oxygen. The high BOD at Spencon site where there are no industries may be due to animal excreta deposited into the river as animals come to drink water and graze along the river bank. COD is very high and it exceeded the regulatory limits of $100 \mathrm{mg} / \mathrm{L}$ set by NEMA [18] at all sites. This is attributable to decomposition of organic matter such as animal and human excreta, plant debris and dead organisms. These results are comparable to other urban rivers whose qualities are influenced by domestic, agricultural and industrial activities that release organic matter and other waste into the river [17] [19] [20] [21].

\section{Spatial Similarity of Study Sites with Cluster Analysis}

Cluster analysis is applied to find out the spatial similarity between the sampling sites, based on the levels of physico-chemical parameters. It grouped the five sampling sites into three statistically significant clusters as depicted by the dendograms (Figure 2 \& Figure 3). Cluster analysis is used in this study because a visual summary of the intra-relationships amongst variations in the study sites can lead to a better understanding of the factors governing the variations. Based on the 19 variables, cluster analysis classified the five sampling sites into three distinct clusters at Dlink/Dmax, according to the level of pollution. This is represented as site of less pollution, moderate pollution and high pollution levels.

For the dry season, cluster 1 comprised of GBK and Spencon sites (Figure 2). These sites had similar water quality because during the dry season, the factory and surrounding environs released little or no waste. Besides, pollutants are not eroded from the surrounding areas of the study sites. Hence, these sites formed cluster 1 with low pollution levels. The higher salinity recorded at GBK sampling site is attributable to discharge of dairy industrial effluent into the river from factory.

Cluster 2 corresponding to moderate pollution is ascribed to Katete site (Figure 2 ). This is because less wastewater is brought to this site since there was 


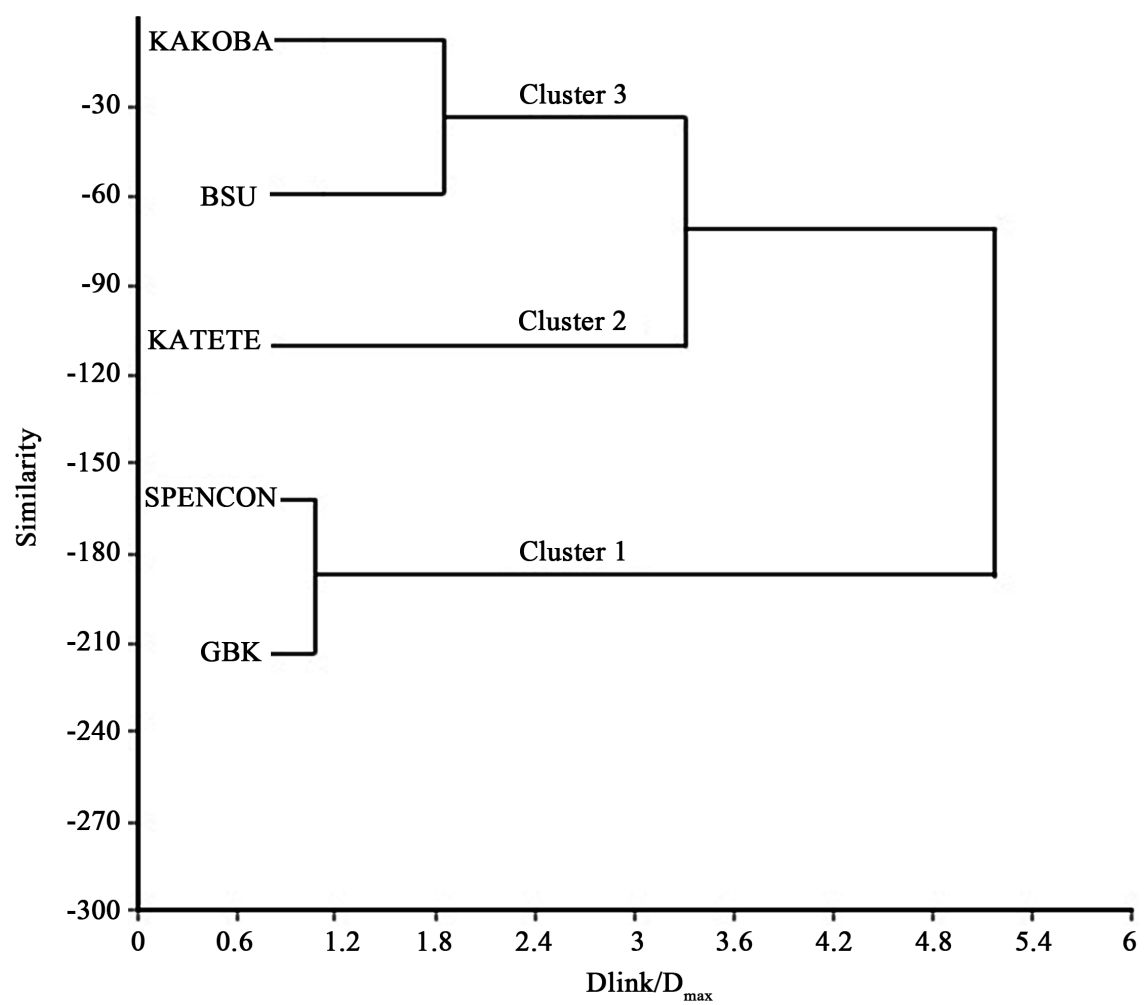

Figure 2. Cluster analysis for water quality parameters of the Rwizi River during the dry season.

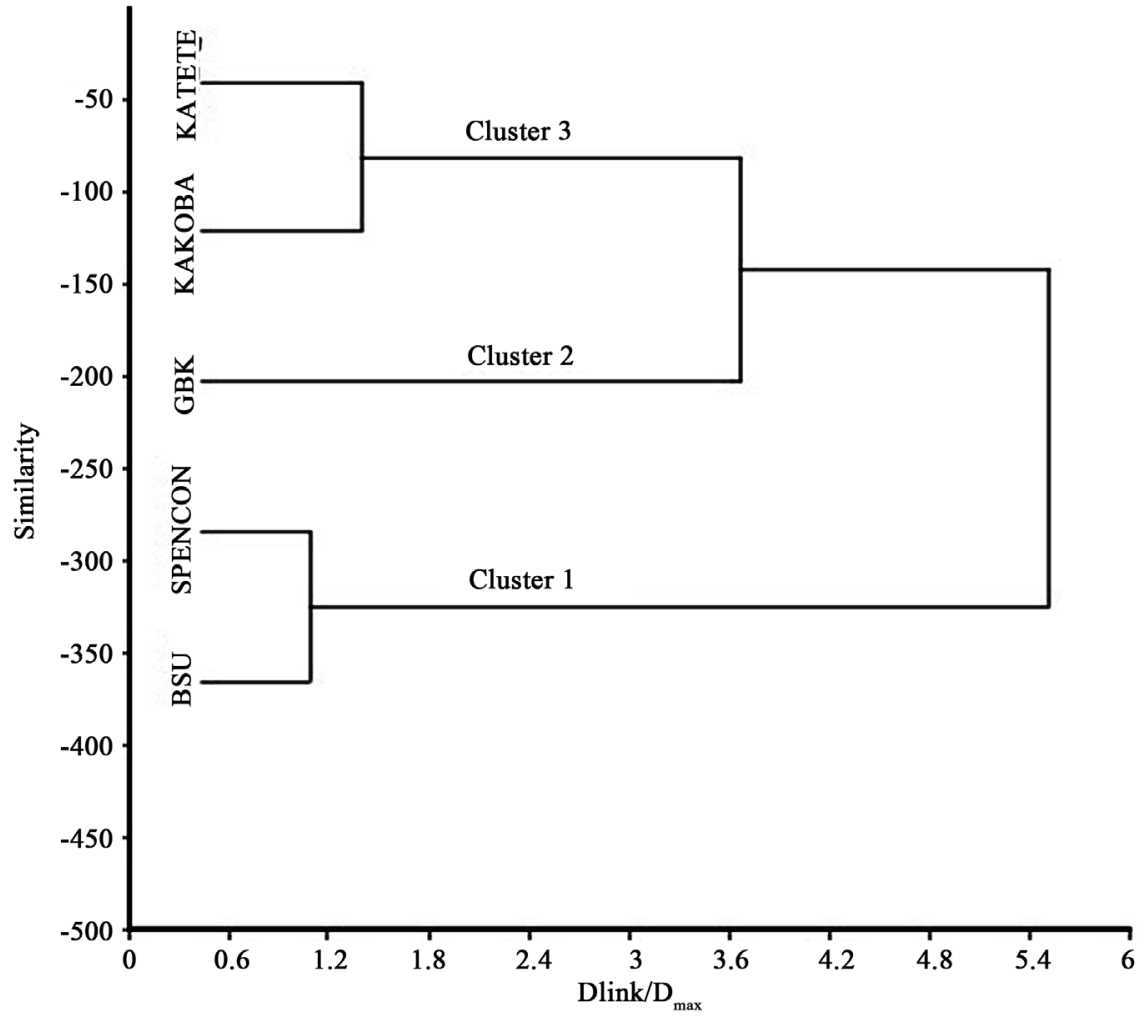

Figure 3. Dendogram of cluster analysis for water quality parameters of the Rwizi River during the wet season. 
no erosion to bring pollutants in the rain storm water. It, therefore, received pollutants principally from the Katete sewage lagoons. In addition, there is a papyrus swamp located upfront from where the effluent from the sewage lagoon passes before entering into the river water presupposing that it purifies the water before reaching the river. Cluster 3 corresponds to the most polluted sites and comprised of Spencon and GBK sites, during the dry season (Figure 2). This is attributed to the intense anthropogenic activities in the catchment due to high human population in the vicinity of the study sites. The sand mining, washing of fabrics and automobiles, slaughtering of animals, as well as animal excreta deposited into the river water as animals come to drink water, affected its quality at these points. It can be inferred here, therefore, that the self-purification capability of the river is weak, during the dry season, which is evident by progressive deterioration of water quality downstream as the river traverses Mbarara $\mathrm{Mu}$ nicipality along the water course. The results of cluster analysis are comparable to those of other similar studies conducted on different rivers [14] [21] [22] [23].

For the wet season, cluster 1 is formed by BSU and Spencon sites with lesspollution levels; while Katete site with moderate pollution level is ascribed to cluster 2. Cluster 3 is formed by Katete and Kakoba sites with high pollution levels. Cluster 1 for wet season comprised of BSU and Spencon sites, depicting relatively less polluted parts of the river (Figure 3). The main sources of pollution at these sites are soil erosion, and animal excreta and domestic waste. Spencon site recorded higher colour measurements due to the erosion from the surrounding environs. At BSU site the high colour measurement value may be attributed to faster flow rate of the river as result of the steep slope which suspends bottom sediments. This is coupled with the economic activities such as sand mining and brick making, which are carried out along the banks of the river. Cluster 2 (GBK) corresponds to moderately polluted site (Figure 3). GBK site had moderate water quality. This site mainly receives pollutants from agricultural, sand mining, urban waste from Rwebikoona Town area and many diary factories located in vicinity of GBK site. These pollution sources account for the measured water quality parameters at this study site. This explained the high sulphate, COD, BOD, iron, manganese, turbidity, TSS, hardness, TDS, salinity, and EC measurement values at the GBK site. In addition, GBK site recorded lower DO and alkalinity concentration than the other study sites partly due to its highly saline waters. Cluster 3 corresponds to the sites with the least water quality. Kakoba and Katete sites ascribed to this cluster. The water quality at the two sites was affected by untreated sewage effluent, urban domestic waste and or/ run off from Mbarara Municipality and agricultural fields. This cluster comprised sites with the highest human population density and thus received higher amount of wastewater. These sites recorded moderately high electrical conductivity and salinity values partly due to contribution of ions from the sewage effluents discharged into the river.

The Katete site receives domestic waste from the human settlements in the surrounding villages and effluents from sewage lagoons as well as waste from 
Mbarara University of Science and Technology (MUST), Mbarara Regional Referral Hospital and environs. Kakoba site receives effluents from the Kakoba sewage lagoons, KSBM ISPAT (Uganda) Limited, a steel rolling mill industry and urban waste from Kakoba market and the surrounding human settlements. This may help explain the observed physico-chemical characteristics observed at the Kakoba and Katete sites. Considering the geolocation of Kakoba and BSU sites along the river, the improved water quality at BSU site reveals the selfpurification ability of the river by swampy plants.

Increase in turbidity 92.7 to $98.7 \mathrm{NTU}$ in wet season and from 98.3 to 105 NTU in dry season from Spencon site to GBK site and then from 124.7 NTU at Katete site to $176.3 \mathrm{NTU}$ at Kakoba site indicated the pollutants were entering the river from the most densely populated part of Mbarara Municipality where numerous activities are carried out. The iron, calcium, manganese, and salinity which can be termed as salinity factors, were mainly due to geochemical phenomena in the river water [4] [24]. The increase in concentration of manganese from $0.077 \mathrm{mg} / \mathrm{L}$ at Katete site to $0.181 \mathrm{mg} / \mathrm{L}$ at Kakoba site indicates the contribution of the, steel rolling mill industry located in Kakoba in the vicinity of River Rwizi. The increase in total iron concentration from $0.511 \mathrm{mg} / \mathrm{L}$ at Spencon site to $0.737 \mathrm{mg} / \mathrm{L}$ at GBK site shows influx of iron into the river due to commercial and industrial establishments. Also, the concentration of iron in all the study sites was above the regulatory limit in drinking water [15]. GBK site recorded higher salinity values and conductivity than the other four study sites. This is attributed to the waste water effluent from the GBK factory as well as Rwebikoona market and its environs, which contribute chemicals into the river. Total iron was highest at GBK site due to mainly the abattoir effluents from several slaughter points situated between Spencon site and GBK. In addition to the anthropogenic influences, it can be seen that changes in the water chemistry may be due to processes such as dilution or abrupt changes resulting from localised contamination at different sampling sites. There are other reports with similar results on urban river water quality [21] [25].

\section{Conclusion}

In this study, cluster analysis is utilized to evaluate variations in surface water quality of River Rwizi section in Mbarara Municipality. This study revealed that water pollution resulted primarily from domestic waste water, agricultural runoff, industrial effluents and natural hydrologic processes. All the study sites recorded iron, manganese, $\mathrm{COD}$ and $\mathrm{pH}$ (wet season) above the WHO allowable maximum limit in surface water. Also, some sites showed higher manganese, BOD and TDS than the standards. Cluster analysis grouped the five study sites into three statistically meaningful groups: low pollution (Spencon, GBK), moderate (Katete) and high pollution (BSU, Kakoba) for dry season; while for rain season, the order is: low pollution (BSU, Spencon), moderate (GBK) and high pollution (Kakoba, Katete), basing on similarity of water quality variables. Bas- 
ing on the three clustered regions in each season, the sources for high pollution and moderate pollution sites are anthropogenic; including industrial and urban (domestic) wastes, sewage effluent, and agricultural runoff. For low pollution sites, the domestic and agricultural runoffs are the main sources of pollution. Based on the results, the water may be used for irrigation or be treated first for drinking and domestic use. It is recommended therefore that the vegetation along the river banks and River Rwizi catchment be restored to reduce the impact of erosion into the river. Also buffer zones should be created through rejuvenation of papyrus swamps to naturally purify the waste water before joining the river. It is important that Uganda National Environment Management Authority encourages industries to treat their effluents before they are released into the river and it should monitor compliance by regularly analysing samples of industrial effluents entering the river. It is therefore important that the environment and water management bodies work together to restore river-line ecosystems throughout the country and particularly for River Rwizi which is on the verge of dying.

\section{Acknowledgements}

The authors acknowledge the laboratories of Kasese Cobalt Company Limited and National Water and Sewerage Corporation (Uganda) where the laboratory analyses of water samples were done.

\section{Conflicts of Interest}

The authors declare that they have no conflict of interest.

\section{References}

[1] Shrestha, S. and Kazama, F. (2007) Assessment of Surface Water Quality Using Multivariate Statistical Techniques: A Case Study of the Fuji River Basin, Japan. Environmental Modelling \& Software, 22, 464-475. https://doi.org/10.1016/j.envsoft.2006.02.001

[2] Singh, K.P., Malik, A. and Sinha, S. (2005) Water Quality Assessment and Apportionment of Pollution Sources of Gomti River (India) Using Multivariate Statistical Techniques-A Case Study. Analytica Chimica Acta, 538, 355-374. https://doi.org/10.1016/j.aca.2005.02.006

[3] Eliku, T. and Leta, S. (2018) Spatial and Seasonal Variation in Physicochemical Parameters and Heavy Metals in Awash River, Ethiopia. Applied Water Science, 8, 177. https://doi.org/10.1007/s13201-018-0803-x

[4] Pejman, A.H., Bidhendi, G.R.N., Karbassi, A.R., Mehrdadi, N. and Bidhendi, M.E. (2009) Evaluation of Spatial and Seasonal Variations in Surface Water Quality Using Multivariate Statistical Techniques. International Journal of Environmental Science \& Technology, 6, 467-476. https://doi.org/10.1007/BF03326086

[5] Egor, M., Mbabazi, J. and Ntale, M. (2014) Heavy Metal and Nutrient Loading of River Rwizi by Effluents from Mbarara Municipality, Western Uganda. International Journal of Chemical Material and Environmental Research, 2, 36-47.

[6] Helena, B., Pardo, R., Vega, M., Barrado, E., Fernandez, J.M. and Fernandez, L. (2000) 
Temporal Evolution of Groundwater Composition in an Alluvial Aquifer (Pisuerga River, Spain) by Principal Component Analysis. Water Research, 34, 807-816. https://doi.org/10.1016/S0043-1354(99)00225-0

[7] Kyosingira, F.W., Mwesigwa, D.N., Twikirize, D. and Twinomuhangi, M. (2011) The Declining Trends of Water Resources in Uganda; A Case Study of River Rwizi, Lake Wamala, Lake Victoria Catchments and Representative Ground Water Monitoring Stations. Water Resources Monitoring and Assessment Division, Department of Monitoring and Assessment, Directorate of Water Resources Management, Entebbe.

[8] Mugonola, B., Deckers, J., Poesen, J., Isabirye, M. and Mathijs, E. (2013) Adoption of Soil and Water Conservation Technologies in the Rwizi Catchment of South Western Uganda. International Journal of Agricultural Sustainability, 11, 264-281. https://doi.org/10.1080/14735903.2012.744906

[9] Ojok, W., Wasswa, J. and Ntambi, E. (2017) Assessment of Seasonal Variation in Water Quality in River Rwizi Using Multivariate Statistical Techniques, Mbarara Municipality, Uganda. Journal of Water Resource and Protection, 9, 83-97. https://doi.org/10.4236/jwarp.2017.91007

[10] American Public Health Association (APHA) (1995) Standard Methods for the Examination of Water and Wastewater. Volume 21, American Public Health Association, Washington DC.

[11] Mendham, J. (2006) Vogels Textbook of Quantitative Chemical Analysis. Pearson Education, India.

[12] Mazlum, N., Özer, A. and Mazlum, S. (1999) Interpretation of Water Quality Data by Principal Components Analysis. Turkish Journal of Engineering and Environmental Sciences, 23, 19-26.

[13] Johnson, R.A. and Wichern, D.W. (2002) Applied Multivariate Statistical Analysis. Volume 5, Prentice Hall, Upper Saddle River, NJ.

[14] Barakat, A., El Baghdadi, M., Rais, J., Aghezzaf, B. and Slassi, M. (2016) Assessment of Spatial and Seasonal Water Quality Variation of Oum Er Rbia River (Morocco) Using Multivariate Statistical Techniques. International Soil and Water Conservation Research, 4, 284-292. https://doi.org/10.1016/j.iswcr.2016.11.002

[15] WHO (2011) Guidelines for Drinking-Water Quality. World Health Organization, 303-304.

[16] GEMS (2005) Water Programme.

[17] Gupta, N., Pandey, P. and Hussain, J. (2017) Effect of Physicochemical and Biological Parameters on the Quality of River Water of Narmada, Madhya Pradesh, India. Water Science, 31, 11-23. https://doi.org/10.1016/j.wsj.2017.03.002

[18] NEMA (2001) National Standards for Portable Water. National Environment Management Authority, Kampala, Uganda.

[19] Chapman, D.V. and Organization, W.H. (1996) Water Quality Assessments: A Guide to the Use of Biota, Sediments and Water in Environmental Monitoring. CRC Press, London. https://doi.org/10.4324/NOE0419216001

[20] Goher, M.E., Hassan, A.M., Abdel-Moniem, I.A., Fahmy, A.H. and El-Sayed, S.M. (2014) Evaluation of Surface Water Quality and Heavy Metal Indices of Ismailia Canal, Nile River, Egypt. The Egyptian Journal of Aquatic Research, 40, 225-233. https://doi.org/10.1016/j.ejar.2014.09.001

[21] Zabihollah, Y., Ahmad, T., Kamran, N., Younes, Y. and Aliakbar, Y. (2013) Assessment of the Surface Water Quality in Tajan River Basin, Iran. Life Science Journal, 10, 775-780. 
[22] Singh, K.P., Malik, A., Mohan, D. and Sinha, S. (2004) Multivariate Statistical Techniques for the Evaluation of Spatial and Temporal Variations in Water Quality of Gomti River (India) - A Case Study. Water Research, 38, 3980-3992.

https://doi.org/10.1016/j.watres.2004.06.011

[23] Juahir, H., Zain, S.M., Yusoff, M.K., Hanidza, T.I.T., Armi, A.S.M., Toriman, M.E. and Mokhtar, M. (2011) Spatial Water Quality Assessment of Langat River Basin (Malaysia) Using Environmetric Techniques. Environmental Monitoring and Assessment, 173, 625-641. https://doi.org/10.1007/s10661-010-1411-X

[24] Zhang, B., Song, X., Zhang, Y., Han, D., Tang, C., Yu, Y. and Ma, Y. (2012) Hydrochemical Characteristics and Water Quality Assessment of Surface Water and Groundwater in Songnen Plain, Northeast China. Water Research, 46, 2737-2748. https://doi.org/10.1016/j.watres.2012.02.033

[25] Garizi, A.Z., Sheikh, V. and Sadoddin, A. (2011) Assessment of Seasonal Variations of Chemical Characteristics in Surface Water Using Multivariate Statistical Methods. International Journal of Environmental Science \& Technology, 8, 581-592. https://doi.org/10.1007/BF03326244 